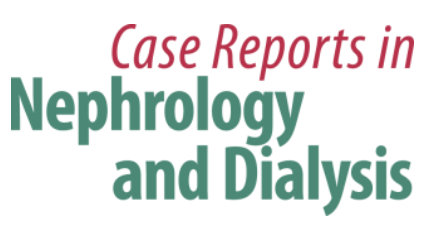

\title{
Progression of Monoclonal Gammopathy with Undetermined Significance to Multiple Myeloma Diagnosed by Kidney Biopsy: A Case Report
}

\author{
Jin Hae Kim ${ }^{a}$ Ji Won Kim ${ }^{a}$ Young Nam Kim ${ }^{a}$ Hye In Kim ${ }^{a}$ \\ Jun Young Kim ${ }^{a}$ Ghee Young Kwon ${ }^{c}$ Kihyun Kim ${ }^{d}$ Hye Ryoun Jang ${ }^{b}$ \\ ${ }^{a}$ Department of Medicine, ${ }^{b}$ Division of Nephrology, Department of Medicine, ${ }^{c}$ Department \\ of Pathology, and ${ }^{\mathrm{d} D}$ Division of Hematology-Oncology, Department of Medicine, Samsung \\ Medical Center, Sungkyunkwan University School of Medicine, Seoul, Korea
}

\section{Key Words}

Multiple myeloma $\cdot$ Monoclonal gammopathy of undetermined significance $\cdot$ Proteinuria

\begin{abstract}
Monoclonal gammopathy with undetermined significance (MGUS) carries a risk of progression to multiple myeloma, and progression is usually diagnosed with changes in M-protein or bone marrow biopsy. We report a case of 62-year-old female patient showing MGUS progression to multiple myeloma without significant changes in M-protein but diagnosed by kidney biopsy. During the follow-ups, azotemia and tubular proteinuria were aggravated without elevation of M-protein. Kidney biopsy showed intratubular and glomerular inclusions associated with plasma cell dysplasia. The progression of MGUS to multiple myeloma was diagnosed by this kidney biopsy. The patient's renal function and tubular proteinuria were markedly improved after chemotherapy.

(c) 2015 S. Karger AG, Basel
\end{abstract}

\section{Introduction}

Monoclonal gammopathy with undetermined significance (MGUS) is a premalignant condition that can progress to multiple myeloma, Waldenstrom macroglobulinemia, amyloid

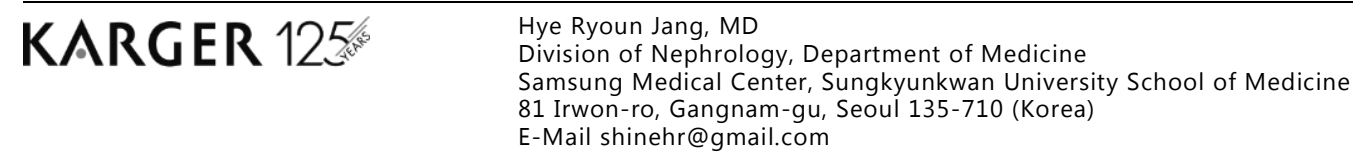




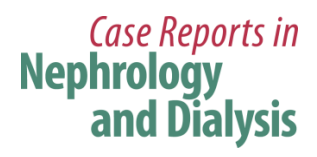

Case Rep Nephrol Dial 2015;5:180-186

DOI: $10.1159 / 000439267$

(C) 2015 S. Karger AG, Basel

www.karger.com/cnd

Kim et al.: Progression of Monoclonal Gammopathy with Undetermined Significance to Multiple Myeloma Diagnosed by Kidney Biopsy: A Case Report

light-chain amyloidosis, or other lymphoproliferative disorder. A monoclonal spike (Mprotein) on serum protein electrophoresis is known to be the most important follow-up tool for MGUS, which is usually followed up regularly by a hematologist to monitor disease progression [1]. We report a case of progression to multiple myeloma from MGUS diagnosed by kidney biopsy in a 62-year-old female patient who presented with aggravation of azotemia and proteinuria without elevation of serum M-protein.

\section{Case Description}

A 62-year-old woman with no significant medical history was diagnosed with MGUS on a regular check-up in October 2009. She was followed up with laboratory tests focusing on her MGUS status, including serum and 24-hour urine simple protein electrophoresis, serum free light chains, and serum IgG, IgA, and IgM every 6 months by a hematologist at Samsung Medical Center.

Two years later, her serum creatinine was elevated from the baseline creatinine level of 1.14 to $1.43 \mathrm{mg} / \mathrm{dl}$ with aggravation of proteinuria. Her serum M-protein level increased to $0.31 \mathrm{~g} / \mathrm{dl}$, compared with $0.21 \mathrm{~g} / \mathrm{dl}$ measured 6 months previously. The ratio of serum $\kappa$ free light chains (FLC) to $\lambda$ FLC rose to 22.14 from 12.62, accompanied by elevation of $\kappa$ FLC up to $320.7 \mathrm{mg} / \mathrm{l}$ from $191.01 \mathrm{mg} / \mathrm{l}$. The patient was sent to the nephrology division as she had acute kidney injury (AKI). The spot urine protein-to-creatinine ratio was $1.22 \mathrm{mg} / \mathrm{mg}$, and the albumin-to-creatinine ratio was $201.85 \mu \mathrm{g} / \mathrm{mg}$. A kidney biopsy was performed to evaluate the cause of the AKI and tubular proteinuria. The kidney biopsy result showed acute tubular damage with mild atrophic features and interstitial fibrosis and mild mononuclear infiltration. Her nephrologist then began regular follow-up laboratory tests with her every 3 months, including estimated glomerular filtration rate and the spot urine albumin-tocreatinine and protein-to-creatinine ratios. Her renal function and degree of proteinuria maintained at about $1.3 \mathrm{mg} / \mathrm{dl}$ of serum creatinine and $1.3 \mathrm{mg} / \mathrm{mg}$ of spot urine protein-tocreatinine ratio.

Two years later (in July 2013), the level of serum creatinine rose to $1.68 \mathrm{mg} / \mathrm{dl}$, and the spot urine protein-to-creatinine ratio was $1.34 \mathrm{mg} / \mathrm{mg}$. After 2 more months, her serum creatinine level rose again to $1.78 \mathrm{mg} / \mathrm{dl}$, the spot urine protein-to-creatinine ratio rose to $1.66 \mathrm{mg} / \mathrm{mg}$, and the spot urine albumin-to-creatinine ratio was $269.21 \mu \mathrm{g} / \mathrm{mg}$. The amount of serum M-protein decreased to $0.27 \mathrm{~g} / \mathrm{dl}$ from $0.30 \mathrm{~g} / \mathrm{dl}$ measured 6 months previously. However, the serum $\kappa / \lambda$ FLC ratio was elevated from 27.1 to 39.84 caused by elevation of serum $\kappa$ FLC level to $586.47 \mathrm{mg} / \mathrm{l}$. No other symptoms or signs, such as hypercalcemia, bone pain, or anemia, suggested progression to multiple myeloma. A second kidney biopsy was performed, and the light microscopy result showed minimal tubular atrophy and acute tubular damage accompanied by minimal interstitial fibrosis and mild mononuclear infiltration. However, the electron microscope examination revealed that some tubular epithelial cells and podocytes were filled with electron-dense intracytoplasmic inclusions, which were also found in the urinary space (fig. 1). That result suggested Bence-Jones crystalline nephropathy associated with plasma cell dyscrasia. Therefore, the patient received a thorough hematologic workup even though the level of M-protein had not increased.

A bone marrow biopsy showed normocellular marrow with proliferation of monoclonal plasma cells, suggesting the progression of MGUS to plasma cell myeloma (IgG, $\kappa$ ). A skeletal $\mathrm{X}$-ray survey found compression fractures in the T8 and T9 vertebral bodies. A subsequent spine MRI revealed a focal hypointense lesion in the right articular process of the T5 and T7 vertebral bodies involved by multiple myeloma. Finally, she was diagnosed with multiple 


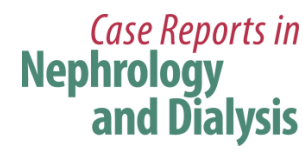

\begin{tabular}{l|l}
\hline Case Rep Nephrol Dial 2015;5:180-186 \\
\hline DOI: $10.1159 / 000439267$ & $\begin{array}{l}\text { C 2015 S. Karger AG, Basel } \\
\text { www.karger.com/cnd }\end{array}$ \\
\hline
\end{tabular}

Kim et al:: Progression of Monoclonal Gammopathy with Undetermined Significance to Multiple Myeloma Diagnosed by Kidney Biopsy: A Case Report

myeloma involving kidney and bone. She then began chemotherapy with a regimen of melphalan/dexamethasone weekly to treat the multiple myeloma. After 4 cycles of chemotherapy over 5 months, complete remission was achieved. The serum creatinine level decreased to $1.33 \mathrm{mg} / \mathrm{dl}$, and the spot urine protein-to-creatinine ratio also decreased to $0.27 \mathrm{mg} / \mathrm{mg}$ (fig. 2). No abnormal band was observed on immunofixation tests of serum or spot urine. After 8 cycles of chemotherapy, serum creatinine was normalized to the level of $1.05 \mathrm{mg} / \mathrm{dl}$, and spot urine protein-to-creatinine ratio decreased to $0.22 \mathrm{mg} / \mathrm{mg}$.

\section{Discussion}

We report the case of a 62-year-old female patient diagnosed by kidney biopsy with multiple myeloma progression from MGUS without significant changes in M-protein. Because of aggravation of azotemia without M-protein changes, she was sent from the hematology division to the nephrology division 2 years after her first diagnosis with MGUS. Then, through monitoring of renal function and proteinuria, a kidney biopsy was performed in time, and chemotherapy for multiple myeloma was initiated. This case presentation is meaningful for early detection of multiple myeloma progression in an MGUS patient with renal involvement by monitoring kidney function and proteinuria using a multidisciplinary medical approach combining hematology and nephrology.

Multiple myeloma is a plasma cell neoplasm characterized by myeloma-related end organ damage caused by an overproduction of monoclonal immunoglobulin, and is almost always preceded by an asymptomatic premalignant stage termed MGUS [2, 3]. MGUS is defined by the presence of serum M-protein $(<3 \mathrm{~g} / \mathrm{dl})$, the clonal plasma cell population in the bone marrow $(<10 \%)$, and the absence of end-organ damage such as hypercalcemia, renal insufficiency, anemia, and lytic bone lesions [4]. The risk for progression of MGUS to multiple myeloma or other plasma cell dyscrasias is approximately 1\% per year [5]. The 2010 International Myeloma Working Group (IMWG) guidelines suggest follow-ups on the basis of the risk stratification model for progression of MGUS made by Rajkumar et al. [6]. Patients with low-risk MGUS (M-protein $<15 \mathrm{~g} / \mathrm{l}$, IgG, and a normal free light chain) should be followed up with serum protein electrophoresis for 6 months, and if stable can be followed up every 2-3 years or when symptoms suggest that end-organ damage has developed. Intermediate or high-risk patients should be followed up with serum protein electrophoresis and a complete blood cell count for 6 months and yearly thereafter [4]. A bone marrow biopsy and skeletal survey are always indicated in patients with MGUS with unexplained anemia, renal insufficiency, hypercalcemia, skeletal lesion, or an increase in M-protein of $>25 \%$. Because multiple myeloma remains an incurable disease with serious myeloma-related complications such as pathologic fractures or renal failure, close monitoring has been recommended for MGUS patients to detect malignant transformation before the onset of serious complications [7]. Early detection of kidney diseases involved with monoclonal protein is important because rapid intervention targeting the overproduction of monoclonal immunoglobulins is the best way to preserve and restore kidney function [8].

In this case, when azotemia and tubular proteinuria were aggravated without elevation of serum or urine M-protein or other organ damage, a kidney biopsy was performed for differential diagnosis [9]. The first kidney biopsy revealed minor changes in the tubules and glomeruli. It found no evidence of specific kidney injury associated with monoclonal gamma globulin deposits, but to monitor her kidney function and proteinuria, she was followed up by both a nephrologist and a hematologist every 3 and 6 months, respectively. Two years after her first kidney biopsy, the serum creatinine level and protein-to-creatinine ratio in 


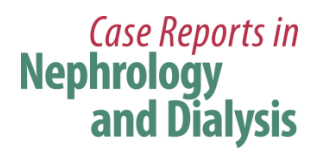

\begin{tabular}{l|l}
\hline Case Rep Nephrol Dial 2015;5:180-186 \\
\hline DOI: 10.1159/000439267 & $\begin{array}{l}\text { ○ 2015 S. Karger AG, Basel } \\
\text { www.karger.com/cnd }\end{array}$ \\
\hline
\end{tabular}

Kim et al:: Progression of Monoclonal Gammopathy with Undetermined Significance to Multiple Myeloma Diagnosed by Kidney Biopsy: A Case Report

spot urine were elevated without significant changes in M-protein. The second kidney biopsy revealed intratubular and glomerular inclusions associated with plasma cell dysplasia in the electron microscope examination, although the immunofluorescence staining for $\kappa$ and $\lambda$ was negative. The final pathologic diagnosis was Bence-Jones crystalline nephropathy. After the hematologic and skeletal workup, progression of MGUS to multiple myeloma involving bone and kidney was finally diagnosed. Effective chemotherapy could be started because of the early diagnosis of disease transformation.

Recently, the term monoclonal gammopathy with renal significance (MGRS) has emerged which should be distinguished from MGUS. MGRS can be defined as kidney disease caused by the deposition of monoclonal immunoglobulin secreted by a nonmalignant B-cell clone, and the hematologic disorder is generally consistent with MGUS [10, 11]. MGRSrelated kidney diseases include a wide spectrum of diseases such as amyloid light-chain amyloidosis, light chain deposition disease, immunotactoid glomerulopathy, and proliferative glomerulonephritis with monoclonal immunoglobulin deposits [8]. MGRS is associated with high morbidity, and treatment is mandatory and sometimes urgent to prevent renal functional deterioration [12]. If renal functional deterioration or proteinuria develops in patients with monoclonal gammopathy, MGRS should be suspected, and a kidney biopsy is indicated to assess the MGRS type, evaluate its severity, and check for other renal diseases [11]. Early recognition of kidney diseases involving monoclonal protein is crucial because suppression of monoclonal immunoglobulin secretion by chemotherapy often improves outcomes [13].

In conclusion, collaborative follow-ups by both a hematologist and a nephrologist are necessary for MGUS patients with renal involvement such as proteinuria, hematuria, or renal insufficiency, not only for early detection of disease progression but also for initiation of therapy at an appropriate time. Appropriate assessment of changes in renal function or other renal signs of disease progression, including proteinuria, hematuria, glycosuria, and phosphaturia, could be carried out for accurate diagnosis of MGUS patients through followups by nephrologists. Therefore, it is important for nephrologists to determine the renal significance of M-protein and collaborate with hematologists to timely initiate effective chemotherapy.

\section{Disclosure Statement}

There are neither conflicts of interest nor financial support to declare.

\section{References}

1 Blade J: Clinical practice. Monoclonal gammopathy of undetermined significance. N Engl J Med 2006;355:2765-2770.

-2 Palumbo A, Anderson K: Multiple myeloma. N Engl J Med 2011;364:1046-1060.

-3 Landgren O, Kyle RA, Pfeiffer RM, Katzmann JA, Caporaso NE, Hayes RB, Dispenzieri A, Kumar S, Clark RJ, Baris D, Hoover R, Rajkumar SV: Monoclonal gammopathy of undetermined significance (MGUS) consistently precedes multiple myeloma: a prospective study. Blood 2009;113:5412-5417.

-4 Kyle RA, Durie BG, Rajkumar SV, Landgren O, Blade J, Merlini G, Kroger N, Einsele H, Vesole DH, Dimopoulos M, San Miguel J, Avet-Loiseau H, Hajek R, Chen WM, Anderson KC, Ludwig H, Sonneveld P, Pavlovsky S, Palumbo A, Richardson PG, Barlogie B, Greipp P, Vescio R, Turesson I, Westin J, Boccadoro M: Monoclonal gammopathy of undetermined significance (MGUS) and smoldering (asymptomatic) multiple myeloma: IMWG consensus perspectives risk factors for progression and guidelines for monitoring and management. Leukemia 2010;24:1121-1127.

5 Kyle RA, Therneau TM, Rajkumar SV, Offord JR, Larson DR, Plevak MF, Melton LJ 3rd: A long-term study of prognosis in monoclonal gammopathy of undetermined significance. N Engl J Med 2002;346:564-569. 
Kim et al.: Progression of Monoclonal Gammopathy with Undetermined Significance to Multiple Myeloma Diagnosed by Kidney Biopsy: A Case Report

6 Rajkumar SV, Kyle RA, Therneau TM, Melton LJ 3rd, Bradwell AR, Clark RJ, Larson DR, Plevak MF, Dispenzieri A, Katzmann JA: Serum free light chain ratio is an independent risk factor for progression in monoclonal gammopathy of undetermined significance. Blood 2005;106:812-817.

7 Bianchi G, Kyle RA, Colby CL, Larson DR, Kumar S, Katzmann JA, Dispenzieri A, Therneau TM, Cerhan JR, Melton LJ 3rd, Rajkumar SV: Impact of optimal follow-up of monoclonal gammopathy of undetermined significance on early diagnosis and prevention of myeloma-related complications. Blood 2010;116:20192025; quiz 2197.

-8 Leung N, Bridoux F, Hutchison CA, Nasr SH, Cockwell P, Fermand JP, Dispenzieri A, Song KW, Kyle RA: Monoclonal gammopathy of renal significance: when MGUS is no longer undetermined or insignificant. Blood 2012;120:4292-4295.

-9 Merlini G, Palladini G: Differential diagnosis of monoclonal gammopathy of undetermined significance. Hematology Am Soc Hematol Educ Program 2012;2012:595-603.

10 Parry HM, Pratt G, Hutchison CA: Monoclonal gammopathy of undetermined significance: an update for nephrologists. Adv Chronic Kidney Dis 2012;19:291-296.

11 Bridoux F, Leung N, Hutchison CA, Touchard G, Sethi S, Fermand JP, Picken MM, Herrera GA, Kastritis E, Merlini G, Roussel M, Fervenza FC, Dispenzieri A, Kyle RA, Nasr SH: Diagnosis of monoclonal gammopathy of renal significance. Kidney Int 2015;87:698-711.

12 Fermand JP, Bridoux F, Kyle RA, Kastritis E, Weiss BM, Cook MA, Drayson MT, Dispenzieri A, Leung N: How I treat monoclonal gammopathy of renal significance (MGRS). Blood 2013;122:3583-3590.

13 Heher EC, Goes NB, Spitzer TR, Raje NS, Humphreys BD, Anderson KC, Richardson PG: Kidney disease associated with plasma cell dyscrasias. Blood 2010;116:1397-1404. 


\section{Case Reports in \\ Nephrology and Dialysis}

\begin{tabular}{l|l}
\hline \multicolumn{2}{l}{ Case Rep Nephrol Dial 2015;5:180-186 } \\
\hline DOI: 10.1159/000439267 & $\begin{array}{l}\text { ○ 2015 S. Karger AG, Basel } \\
\text { www.karger.com/cnd }\end{array}$ \\
\hline
\end{tabular}

Kim et al.: Progression of Monoclonal Gammopathy with Undetermined Significance to Multiple Myeloma Diagnosed by Kidney Biopsy: A Case Report
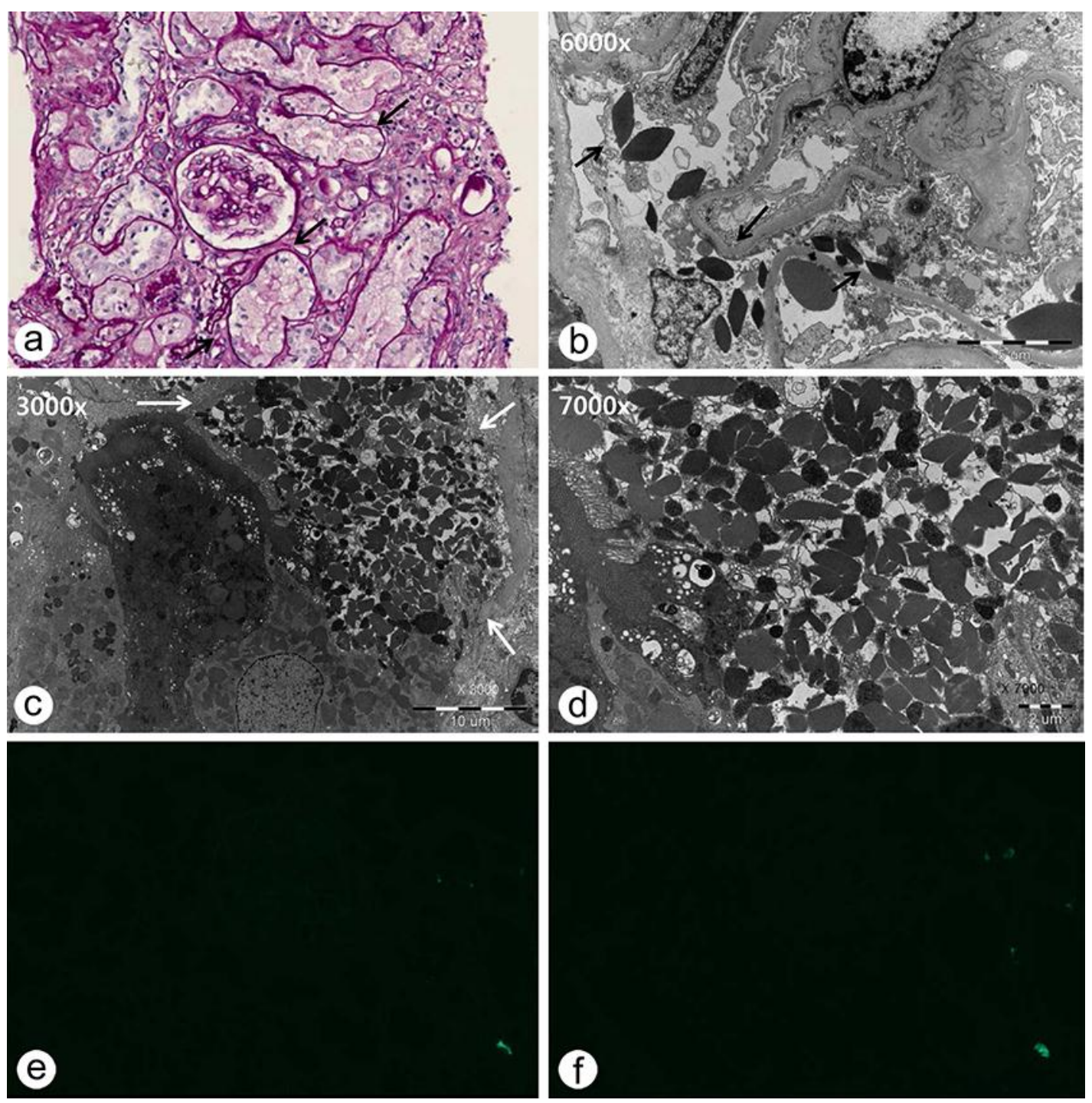

Fig. 1. Features of the second kidney biopsy. a Under light microscopy, tubular epithelial cells contained vacuolated cytoplasm (arrows) accompanied by minimal interstitial fibrosis and mild mononuclear infiltration. Periodic acid-Schiff stain. $\times 400$. $b-d$ Electron microscopy revealed electron-dense intracytoplasmic inclusions in the epithelial cells of some tubules as well as in the urinary space and the podocytes of some glomeruli (black and white arrows). These inclusions were variable in size and ovoid to angular in shape. Original magnifications, $\times 6,000, \times 3,000$, and $\times 7,000$, respectively. e Immunofluorescent staining for $\kappa$ is negative in glomeruli. $\times 200$. $f$ Immunofluorescent staining for $\lambda$ is negative in glomeruli. $\times 200$. 
Kim et al.: Progression of Monoclonal Gammopathy with Undetermined Significance to Multiple Myeloma Diagnosed by Kidney Biopsy: A Case Report

a

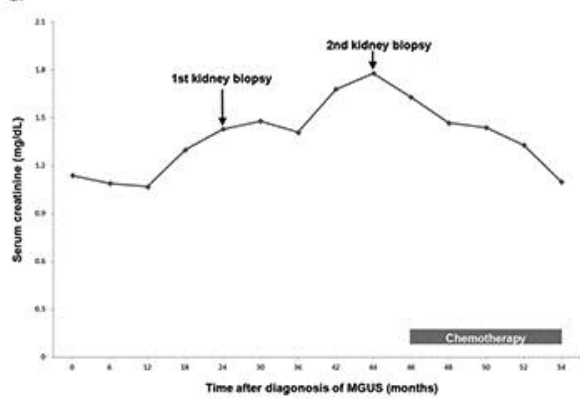

C

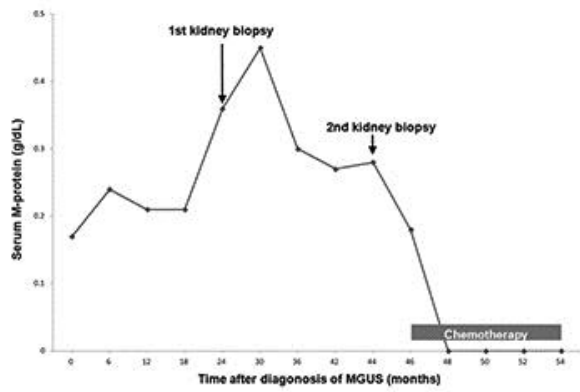

e

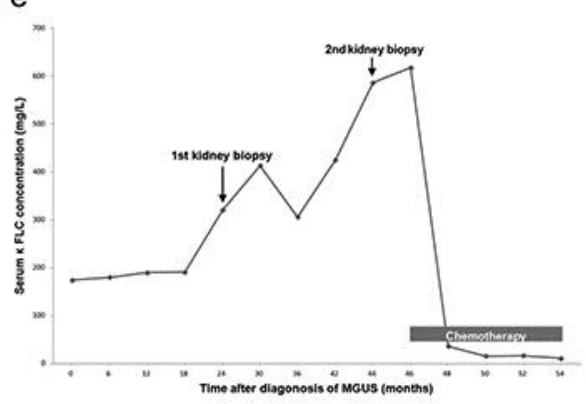

b

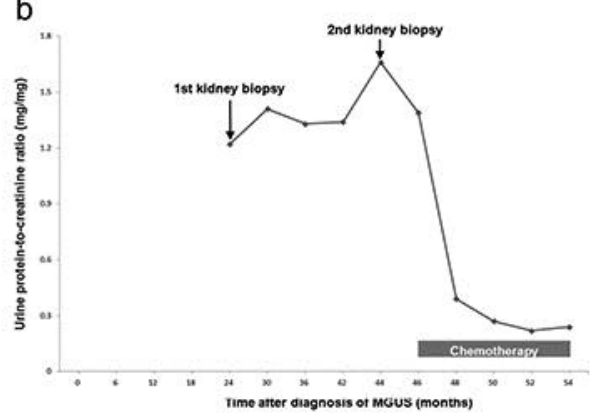

d

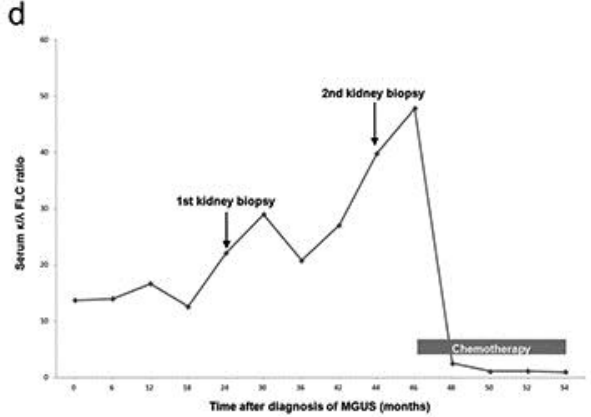

Fig. 2. Clinical course from MGUS to multiple myeloma before and after chemotherapy. a The second kidney biopsy was performed when both azotemia and proteinuria were aggravated without elevation of serum M-protein. After 8 cycles of chemotherapy, serum creatinine levels decreased significantly. b Spot urine protein-to-creatinine levels were also reduced by chemotherapy. c-e Serum M-protein levels and the $\kappa / \lambda$ FLC ratio as well as serum $\kappa$ FLC concentration were normalized after chemotherapy. 